\title{
Los ríos del Pacífico: de accidentes geográficos a construcciones sociales
}

\author{
Sandra Patricia Martínez B.*
}

Resumen: el presente artículo se centra en el papel del transporte fluvial en los procesos de apropiación y configuración territorial de la región Pacífica co lombiana, señalando la necesidad de superar la visión del transporte como el mero movimiento de pasajeros y mercancías, para entenderlo como un proceso de construcción espacial, objeto de la reflexión geográfica. El río ha dejado de ser para los grupos indígenas y negros del Pacífico, un simple medio de transporte y comunicación, para convertirse en un referente identitario, revelador de una re lación dinámica entre los procesos materiales y la imagen subjetiva del territorio.

Palabras clave: geografía del transporte, espacio social, imaginario geográfico, apropiación territorial.

(Aceptado noviembre 2002).

* Socióloga, Universidad Nacional de Colombia. Candidata a Magister en Geografía énfasis en Ordenamiento Territorial. Convenio Universidad Pedagógica y Tecnológica de Colombia- Instituto Geográfico Agustín Codazzi, Bogotá 


\section{Una contextualización necesaria}

La noción del espacio como un producto social, no es nueva en el ámbito de los estudios geográficos. En el largo camino recorrido por la disciplina en la construcción de su cuerpo teórico, la reacción ante el determinismo ambiental que subordinaba la vida social a los condicionamientos del medio natural, se constituye en una de las rupturas fundamentales dentro de la episteme geográfica. En efecto, desde finales del siglo XIX empiezan a imponerse las llamadas concepciones posibilistas, según las cuales, la naturaleza no determina la acción social, sino que le ofrece al hombre un sinnúmero de posibilidades que éste puede aceptar o rechazar libremente (Capel, 1987).

Asimismo, el diálogo con diferentes disciplinas, tales como la antropología, la sociología y la economía, jugaría un papel de primer orden en el viraje de los geógrafos hacia la dinámica social como fundamento mismo de la organización espacial. El surgimiento y desarrollo de la geografía humana, no podrían ser entendidos sin considerar el aporte de las categorías analíticas construidas desde otras disciplinas: la morfología social de Durkheim; la ecología humana apoyada en el evo- lucionismo darwiniano; el concepto de modo de vida acuñado por Vidal de La Blanche; el paisaje y morfología culturales y la noción del homo oeconomicus, son entre otras, categorías que jugarían un papel decisivo en la irrupción de nuevas corrientes geográficas (social, cultural y económica) que hacen cada vez menos concebible la idea de un espacio geográfico independiente de la acción humana ${ }^{1}$.

El papel de la psicología no ha sido menos decisivo en el desarrollo de la geografía humanista. La ruptura con el economicismo y el retorno a los valores individuales propugnados desde esta disciplina, atraerían la atención de los geógrafos de los años sesenta hacia los temas de la percepción y el comportamiento, dando lugar a una nueva tendencia dentro de la geografía, que se apellidaría justamente con estos dos conceptos.

El espacio vivido y la forma como éste es percibido por el hombre, se convierten entonces, en temas de la reflexión geográfica. Mas no es el espacio abstracto y objetivo el que interesa a la geografía de la percepción, sino el espacio subjetivo, modelado por el hombre a partir de sus experiencias, significados y valores en el contexto de su escala espacial personal (Capel, 1981, 1987). Esos mismos significados y valoraciones

\footnotetext{
Para un análisis detallado de las influencias recíprocas entre la geografía y otras disciplinas sociales, véase: Capel, Horacio. Geografía humana y ciencias sociales: una perspectiva histórica. Barcelona: Montesinos, 1989.
}

102 Sandra Patricia Martínez B. 
que explican el desarrollo de sentidos de pertenencia o de rechazo hacia un lugar determinado, ejemplificados en el presente ensayo a través de lo que se ha dado en llamar la cultura acuática de las comunidades negras e indígenas del Pacífico colombiano.

Pero antes de pasar al tema central del artículo, es necesario detenerse en los desarrollos posteriores a la geografía de la percepción y el comportamiento, específicamente en las concepciones fenomenológicas y existencialistas del espacio como problema-clave definidor de la disciplina geográfica.

En franca oposición a la pretensión generalizadora y analítica del modelo positivista propugnado por la geografía cuantitativa, la geografía humanista se vuelca hacia la dimensión subjetiva de la existencia, trasladando el interés desde el espacio abstracto hacia el lugar concreto de la acción (Capel, 1987). Es aquí donde el existencialismo y la fenomenología adquieren especial significación a partir de conceptos como el de espacio vivencial entendido como "el espacio tal y como se manifiesta en la vida humana concreta, el espacio concreto verdadero en que se desarrolla nuestra vida" (Bollnow, 1969).

Desde esta perspectiva, el espacio adquiere una dimensión ontológica, en la medida en que la existencia humana está determinada por su relación con el mismo, lo que permite hablar de la espacialidad como una condición de la existencia humana (Bollnow, 1969). Naturalmente, el espacio vivencial está lleno de significados que varían según localizaciones históricas y geográficas específicas.

La idea de que todo lo que el hombre es y hace está íntimamente ligado con la experiencia del espacio, es compartida por Hall, quien acuña el concepto de proxemística para denominar al «conjunto de observaciones y teorías interrelacionadas con el uso que el hombre hace del espacio» (Hall, 1973). El autor destaca el papel del lenguaje en la forma como el hombre percibe su entorno, en la medida en que el lenguaje constituye un reflejo del mundo sensorial en el que se inscriben individuos pertenecientes a diferentes culturas.

En este contexto de sucesivas rupturas y discontinuidades en el desarrollo epistemológico de la geografía, el transporte ha sido objeto igualmente de diversas miradas según los paradigmas dominantes en geografía: desde la concepción determinista, pasando por el enfoque regional, el posibilismo y la geografía económica hasta el positivismo, tendencia bajo la cual se reconoce el estatus de la geografía del transporte como disciplina académica independiente (Chías, 1994).

Ahora bien, el auge de la geografía humanista a partir de la década de los setenta, ha mostrado la necesidad de abordar el papel del transporte en la 
sociedad, superando la concepción tradicional de este proceso como un simple movimiento de pasajeros y mercancías. Desde esta perspectiva, la geografía del transporte aparece como una ciencia social, capaz de admitir el diálogo con concepciones tan variadas como la geografía de la percepción y las corrientes existencialistas y fenomenológicas, con miras a la comprensión del transporte en tanto proceso espacial. El presente ensayo espera contribuir de una $u$ otra manera a este propósito.

\section{El río en el imaginario geográfico de los habitantes del Pacífico}

Habitualmente, cuando pensamos en el transporte, nos remitimos al modo de transporte terrestre y a la infraestructura vial asociada al mismo. Pero en un país como Colombia, caracterizado por notorias desigualdades territoriales, el transporte terrestre es aún incipiente en muchas de las regiones que lo componen, el estado de la malla vial es deficiente o simplemente no existe. Son regiones desarticuladas de la red vial nacional, a las cuales sólo puede accederse vía aérea, marítima o fluvial y en cuyo interior, tampoco existe comunicación terrestre ni conexión entre las localidades que las conforman. Aunque la conectividad terrestre de estas regiones es débil, muchas veces están mejor comunicadas con los territorios de frontera -a través de redes fluviales, marítimas o aéreas- que con el resto del territorio nacional.

En este breve ensayo, me centraré en el transporte fluvial y su papel en la configuración territorial de la región del Pacífico colombiano.

El Andén Pacífico se extiende a lo largo del occidente colombiano desde la frontera con Panamá hasta el Ecuador, alcanzando una longitud aproximada de $1.300 \mathrm{kms}$. En sentido oriente-occidente se despliega de manera variable entre 80 y $160 \mathrm{kms}$, desde el piedemonte de la cordillera Occidental hasta la franja costera. Su área total cubre aproximadamente 10 millones de hectáreas que representan cerca del $6.2 \%$ del territorio nacional.

Caracterizada por su riqueza natural, la región es considerada una de las más biodiversas del mundo, lo cual se explica en gran parte, gracias a la extensa red de ríos que corren desde la vertiente occidental de la cordillera Occidental hasta desembocar en los océanos Pacífico y Atlántico.

La riqueza fluvial de la región, sumada al escaso número de carreteras que conectan el interior del país con la costa, hacen del río el medio de transporte más importante en el Pacífico.

Históricamente, se dio un poblamiento disperso a lo largo de los ríos, en forma longitudinal y discontinua. Desde los periodos de conquista y colonización, las comunidades indígenas nativas se

104 Sandra Patricia Martínez B. 
vieron obligadas a replegarse hacia las cabeceras de los ríos, como una estrategia de resistencia frente a la dominación española. El desplazamiento de los indígenas hacia la parte alta de los ríos, se vería reforzado por el avance de la población africana introducida como mano de obra esclava, ya que desde finales del siglo XVIII, cimarrones, libertos y mulatos inician un intenso proceso colonizador de las cuencas media y baja de los cursos fluviales. Con la abolición de la esclavitud a mediados del siglo XIX, la población negra liberada continúa el proceso de ocupación, encontrando en las orillas condiciones favorables para el cultivo de productos agrícolas así como para el aprovisionamiento de recursos ícticos (Isacsson, 1976).

Tras la decadencia del sistema esclavista fundado en la explotación de los yacimientos auríferos, un nuevo auge extractivista tendría lugar en la región: el ciclo del caucho, la tagua, las pieles y en menor grado, el cacao, que provocaría el reconocimiento de los afluentes de los principales ríos que bañan la región. De este modo, se prolonga la colonización del territorio del Pacífico, con la incorporación de tierras vírgenes, primero a la explotación y recolección de frutos silvestres y posteriormente, al cultivo de distintos productos agrícolas o a actividades como la pesca y la extracción maderera (Aprile- Gniset, 1994).

Desde entonces, el río se constituyó en la arteria principal de comunicación y transporte, configurando un modelo de ocupación territorial lineal y riberino que determina la movilidad de la población a lo largo de su curso natural. Dicho patrón de asentamiento está asociado a la estrategia económica practicada por los pobladores locales, la cual se fundamenta en una agricultura de rotación, que implica dispersión de cultivos, desplazamientos durante los periodos de labor y la utilización estacional de recursos mineros, de pesca y del bosque.

Alrededor del río se desarrollan las relaciones de parentesco y de intercambio de productos entre la población; es el espacio social por excelencia, en el cual tienen lugar las interacciones cotidianas entre los pobladores ribereños y de éstos con el medio natural. El río se presenta de esta manera como un sistema en el cual se integran las diferentes dimensiones de la vida regional: social, económica, cultural y espacial.

Las identidades de la gente del Pacífico, están entonces íntimamente ligadas al espacio acuático del río, en torno al cual se construyen los imaginarios geográficos locales. Es así como el sentido de pertenencia de los grupos nativos, gira en torno a su identificación con el río o la microcuenca donde éstos han estructurado su modo de vida, por encima de la pertenencia a una delimitación político-administrativa determinada. Refiriéndose a los habitantes del departamento del Chocó, el cual ocupa una gran parte de la 
extensión de la región pacífica, el maestro Fals Borda señala:

"Los grupos ecológicos humanos también tienen sus particularidades interesantes en el Chocó, pues la identificación de ellos se basa en ríos o quebradas. Si se pregunta a un chocoano su lugar de origen no responde con el nombre el pueblo, sino con el del río y el de la corriente en cuya ribera nació, o vive todavía y la identificación topográfica también se basa en los ríos y riachuelos, no en caseríos ni corregimientos. Pero de todos modos existe la identificación especial cuyo fundamento es el río como instrumento de comunicación, transporte e integración social" (Fals Borda, 1958).

En la región Pacífica es palmaria la estrecha relación existente entre identidad y territorio, a través de la cual, es posible comprender la forma como estas comunidades reconocen y se apropian del espacio.

En términos generales, el territorio puede ser considerado como el espacio apropiado por un grupo humano para su reproducción física, social y cultural. Además de ser el espacio físico, es el espacio significado donde se desarrollan las formas de trabajo, los eventos especiales, las relaciones sociales, parentales y políticas; es en fin, el espacio que se construye en la cotidianidad, el espacio en el cual «se afinca la identidad y se percibe la diversidad frente al otro» (Henao, 1990).

De ahí la importancia del río como referente identitario entre estas comunidades, ya que además de ser funcional a las necesidades de abastecimiento de recursos y de comunicación y transporte de la población, es el espacio donde se desarrolla gran parte de los hábitos cotidianos de negros e indígenas, tales como los quehaceres domésticos (lavado de ropa y de enseres), el aseo corporal así como la recreación de adultos y niños. El río es también un espacio de encuentro en el que tienen lugar la mayoría de las celebraciones entre las comunidades negras ribereñas, así como las prácticas rituales indígenas, constituyéndose en el centro del universo mítico de estos grupos sociales.

En tanto sistema, las diferentes partes del río están interconectadas entre sí. De manera que las actividades espaciales de las comunidades asentadas en las cuencas media o alta, condicionan las actividades desarrolladas en la desembocadura del mismo. Ello no solamente en términos del intercambio de productos, sino también en términos de las relaciones de propiedad, ya que en el Pacífico es común encontrar que una misma parentela posea territorios en diferentes sectores de la cuenca fluvial. En efecto, el carácter itinerante de las prácticas productivas de los grupos nativos, determina la ubicación de varias parcelas en distintas fases de

106 Sandra Patricia Martínez B. 
producción, a lo largo de los diques naturales.

Así mismo, el derecho de posesión sobre un territorio está dado por la primera ocupación que se haga de la microcuenca o tramo del río. La familia migrante accede a la tierra virgen e invita a otros parientes a instalar su finca en el lugar, tomando para sí un trecho de vega o dique del río. De este modo, el terreno queda reconocido como propio frente al resto de la comunidad.

En otras palabras, entre todas las partes del río existe una relación continua de la parte alta con la baja y viceversa, y de éstas con el medio físico, lo que implica el conocimiento y dominio del territorio ribereño.

En efecto, la utilización de la red hidrográfica como medio de transporte principal, supone un profundo conocimiento del medio físico, en la medida que la navegación fluvial está fuertemente condicionada por el ciclo natural. Es el caso del régimen de lluvias que incide directamente en el transporte fluvial: los periodos de invierno o fuertes lluvias aumentan el nivel del río, facilitando de esta manera la navegación, mientras que en épocas de escasas lluvias no hay agua suficiente para remontar el río, dificultándose el tránsito por el mismo.

Evidentemente, la variabilidad del proceso de transportación tiene una direc- ta incidencia tanto en la estrategia productiva como en la vida cotidiana de los grupos nativos. Así por ejemplo, el ejercicio de una $u$ otra actividad económica está determinado por las condiciones de navegación fluvial. Cuando éstas son favorables, es posible el traslado de productos agrícolas y forestales, así como el flujo de pasajeros entre distintos caseríos, mientras que al dificultarse la navegabilidad, los pobladores deben dedicarse a otras actividades tales como la minería y las labores de preparación de los terrenos cultivables, así como reducir sus desplazamientos hacia otros centros poblados.

Pero la importancia del río como medio de transporte no sólo se manifiesta en las relaciones materiales; también está presente en el imaginario geográfico, reflejándose en las múltiples formas como el habitante de la región interpreta su mundo. El papel del río como referente geográfico inmediato se hace evidente en la forma como se alude a lugares o distancias específicas. Así por ejemplo, se utilizan expresiones como más arriba o más abajo para señalar la ubicación de una localidad particular respecto a la dirección en la que corre el curso fluvial. El río es definitivamente la autopista de la selva del Pacífico, a tal punto que el nativo muchas veces utiliza el término calle, para referirse a la distancia entre dos puntos sobre una línea recta cuando se mira desde la curva de un río hasta otra. 


\section{El río en el proceso de apropiación territorial del Pacífico}

En términos de la organización del territorio, es posible establecer una estrecha relación entre las redes fluviales y las fases del proceso de apropiación territorial en el Pacífico colombiano, entendiendo que este proceso no se da de una manera lineal y homogénea, según la cual cada fase de la evolución se entronca con la anterior, sino como un proceso dinámico y contradictorio, que admite la coexistencia de dos o más fases en distintos grados de desarrollo en un mismo espacio geográfico.

La fase de aislamiento característica del periodo de conquista y colonización españolas, supuso un proceso de organización territorial, centrado en la explotación minera de los yacimientos de metales preciosos, configurándose un patrón de asentamientos lineales y transitorios a lo largo de los ríos auríferos, siendo el carácter de región de fronte$r a$, la nota predominante en esta etapa del desarrollo histórico del Pacífico.

En segundo lugar, la fase de exploración-explotación, estaría asociada al auge de distintos ciclos extractivos (tagua, caucho, pieles y cacao), que promovieron la intensa movilización de la población en busca de tierras para colonizar, delineando el asentamiento de la población negra en las cuencas media y baja de los cursos fluviales y el replegamiento de los grupos indígenas hacia las cabeceras de los ríos y afluentes.

La tercera fase, de articulación $y$ poblamiento, estaría atravesada por el proceso de colonización agraria de la región, comprendiendo dos subfases a la vez. La primera, denominada por Aprile-Gniset bajo el término de hábitat disperso aislado, comprendió el establecimiento de cultivos como el plátano, la caña, el arroz y los frutales en una franja lineal paralela al río, actividad complementada con la pesca, dada por el acceso directo al río y una pequeña reserva de maderas.

La aparición de nuevas casas construidas por los hijos de la pareja inicial o por parientes y vecinos de la misma, daría lugar al surgimiento de la aldea en forma de hilera única, en la cual, la posesión de cada unidad familiar sobre el hábitat residencial y productivo, se ejerce de acuerdo con las normas consuetudinarias instauradas por la comunidad. Las relaciones de vecindad y de parentesco juegan en este tipo de aldea, un papel de primer orden en la regulación de la propiedad sobre la tierra.

Con el tiempo, se presenta una tendencia hacia la sedentarización, a partir del surgimiento de nuevas habitaciones (treinta aproximadamente), dándose inicio a la fase de apropiación territorial.

108 Sandra Patricia Martínez B. 
El crecimiento demográfico, junto con la diversificación de la actividad productiva, trae consigo la configuración del caserío como centro de acopio y mercadeo y por ende, cambios en la ocupación espacial. Es entonces cuando se hace necesaria la construcción de una segunda calle detrás de la primera, y eventualmente, de una plaza central, alrededor de la cual, se organizan instituciones como la inspección de policía, la escuela o la capilla.

La aldea ha dejado de ser el pequeño núcleo de economía doméstica, donde el trueque y la solidaridad dominaban las relaciones económicas, para convertirse en corregimiento e incluso cabecera municipal, dentro de los cuales, el intercambio mercantil cobra una nueva importancia. Se abre paso entonces, al surgimiento de un núcleo social «policlasista» (Aprile-Gniset, 1992).

A lo largo del presente ensayo, se ha señalado de manera reiterativa, la estrecha relación existente entre los procesos materiales y la imagen subjetiva del territorio. Así, los procesos de diversificación económica y de crecimiento demográfico, asociados a la complejización del modelo urbanístico lineal fluvial, trajeron consigo el arraigo de ciertos patrones de identificación de la población con su territorio y por ende, la movilización social en torno al reconocimiento de su autonomía territorial.
Es así como a partir de la década de los setenta, las comunidades indígenas del Pacífico deciden organizarse para reivindicar sus derechos ancestrales sobre el territorio, luchando por la constitución de resguardos indígenas como única opción de sobrevivencia para estas comunidades. Una década más tarde, las comunidades negras se unirían a la causa de los indígenas y de manera conjunta con ellos, lograrían el reconocimiento legal sobre sus territorios a través de la Ley 70 de 1993.

Una vez más, el río se constituye en eje central de referencia, como lo demuestra explícitamente el texto de la citada ley, cuyo objeto es "reconocer a las comunidades negras que han venido ocupando tierras baldías en las zonas rurales ribereñas de los ríos de la Cuenca del Pacífico, de acuerdo con sus prácticas tradicionales de producción, el derecho a la propiedad colectiva (...)"2 (Ministerio del Interior, 1993).

\section{A manera de conclusión}

Hemos visto el papel de la red fluvial en los procesos de apropiación territorial en el Pacífico colombiano, entendiendo por apropiación territorial no sólo la ocupación de un espacio determinado, sino también la construcción de identidades territoriales asociadas en este caso, a la pertenencia a un río.

${ }^{2}$ El subrayado es nuestro. 
También se ha tratado de demostrar la necesidad de entender el transporte fluvial -y el transporte en general-, como un sistema en el que se entrelazan una serie de relaciones dinámicas y complejas.

Evidentemente, el conjunto particular de relaciones socioespaciales que se tejen en torno al transporte fluvial, se constituye en un tema crucial cuando de ordenar el territorio se trata, más si se tiene en cuenta la profunda significación del río en la vida social de regiones como el Pacífico. En contextos como éste, el Ordenamiento Territorial deja de ser un mero saber técnico-instrumental centrado en la aplicación mecánica de una metodología predeterminada, para convertirse en un ejercicio democrático, donde tengan cabida todos y cada uno de los actores sociales afectados, donde no haya lugar en cambio, al segregacionismo racial, al sectarismo político y a la exclusión en cualquiera de sus manifestaciones.

110 Sandra Patricia Martínez B. 


\section{Bibliografía}

APRILE- GNISET, Jacques. "La colonización del Atrato" en: La ciudad colombiana. Siglo XIX y siglo XX. Vol. II. Bogotá: Biblioteca Banco Popular, 1992.

. Poblamiento, hábitats y pueblos del Pacífico. Cali: Universidad del Valle. Colección de edición previa. Serie Investigación, 1993.

BOLLNOW, Friedrich. Hombre y espacio. Barcelona: Biblioteca Universitaria Labor, 1969.

CAPEL, Horacio. Historia y ciencia en la geografía contemporánea. Barcelona: Barcanova. Temas Universitarios, 1981.

. Las nuevas geografías. Barcelona: Colección Salvat. Temas Clave, 1987.

. Geografía humana y ciencias sociales: una perspectiva histórica. Barcelona: Montesinos, 1989.

CHÍAS BECERRIL, Luis. Geografía del transporte: ámbito internacional y nacional, en: La Geografía Humana en México: institucionalización y desarrollos recientes, Guillermo Aguilar y Omar Moncada (comp.). México: Fondo de Cultura Económica - Universidad Nacional Autónoma de México, 1994.

. Las externalidades como problema emergente del sistema de transporte metropolitano, en: Problemas emergentes en la zona metropolitana de la ciudad de México, Moisés Castillo y Sergio Reyes (coord.). México: UNAM-PUEC, 1997.

FALS BORDA, Orlando. La vivienda tropical húmeda, sus aspectos sociales y físicos como se observan en el Chocó. Bogotá: Centro Interamericano de Vivienda y Planeación, 1958.

HALL, Edward. La dimensión oculta. Enfoque antropológico del uso del espacio. Madrid: Colección Nuevo Urbanismo, Instituto de Estudios de Administración Local, 1973. 
HENAO, Hernán. "Territorios e instituciones de la cultura. En torno a los procesos culturales regionales", en: Imágenes y reflexiones de la cultura en Colombia. Memorias del Foro Nacional para, con, por, sobre la cultura. Bogotá: Instituto Nacional de Cultura, 1990.

Ministerio del Interior. Ley 70, agosto de 1993.

ISACSSON, Sven Erik. "Embera: Territorio y régimen agrario de una tribu selvática bajo la dominación española", en: Tierra, tradición y poder en Colombia. Enfoques antropológicos. Obra a cargo de Nina S. de Friedemann. Bogotá: Instituto Colombiano de Cultura. Biblioteca Básica Colombiana, 1976.

OSLENDER, Ulrich. "Espacio e identidad en el Pacífico colombiano", en: De montes, ríos y ciudades. Territorios e identidades de la gente negra en Colombia. Antropología e Historia- Colciencias, 2001.

112 Sandra Patricia Martínez B. 


\section{Opinión de los Geógrafos frente a los temas de actualidad}


